\title{
Use of the Sentinel Lymph Node Technique Compared to Complete Inguino-femoral Lymph Node Removal in Patients with Invasive Vulvar Cancer in Germany
}

\author{
Verbreitung der Sentinellymphknotentechnik im Vergleich zur kompletten inguinofemoralen \\ Lymphknotenentfernung beim invasiven Vulvakarzinom in Deutschland
}

Authors

Affiliation
F. Kramer, H. Hertel, P. Hillemanns

Gynecology and Obstetrics, Medical School Hanover, Hanover

\section{Key words \\ - Vulvar cancer \\ - sentinel lymph node dissection \\ - complete inguino-femoral lymphadenectomy \\ Schlüsselwörter \\ - Vulvamalignom \\ - Sentinellymphonodektomie \\ - komplette inguinofemorale Lymphonodektomie}

\section{received 26.6.2012 \\ revised $\quad 31.10 .2012$ \\ accepted $\quad 13.12 .2012$}

Bibliography

DOI http://dx.doi.org/

10.1055/s-0032-1328133

Geburtsh Frauenheilk 2013; 73 :

142-147 @ Georg Thieme

Verlag KG Stuttgart . New York. ISSN 0016-5751

\section{Correspondence}

\section{Dr. Frauke Kramer,}

Medical School Hanover

Gynecology and Obstetrics

Hanover

kramer.frauke@

mh-hannover.de

\section{Abstract \\ $\nabla$}

In the current $\mathrm{S} 2$ guidelines, the standard surgical therapy for patients with vulvar cancer also includes inguino-femoral lymphadenectomy. However, in view of the severe side-effects associated with this approach such as problems with wound healing, lymphoceles and lymphoedema, the search is on for alternative treatments that could decrease treatment-associated morbidity and improve patients' quality of life, particularly for node-negative patients. The sentinel lymph node technique is currently the gold standard in the treatment of unifocal breast cancer (clinically negative axilla), and studies on the use of this technique in the treatment of vulvar cancer are promising. To date, the diagnostic accuracy of this method in vulvar cancer has only been evaluated in a single, one-arm, non-randomised, multicentre study. In preparation for a multicentre study, in 2010 we surveyed 41 German hospitals to investigate how often they used the sentinel lymph node technique compared to inguino-femoral lymphadenectomy. The hospitals were grouped according to hospital size and number of patients treated for vulvar cancer. The decision criteria to determine the type of procedure performed were also investigated. Finally, the hospitals were asked whether they would be willing to participate in a prospective clinical study to evaluate the sentinel lymph node technique in patients with vulvar cancer. The majority of surgeons questioned $(73 \%$ ) already had some experience with this technique in patients with vulvar cancer. In our survey, $27 \%$ of hospitals carried out inguino-femoral lymphadenectomy, 10\% used the sentinel lymph node technique, and $63 \%$ used both methods. In $24 \%$ of hospitals, the standard procedure consisted of the sentinel lymph node technique supplemented by inguino-femoral lymphadenectomy. Only $20 \%$ of the institutions surveyed in our study carried out

\section{Zusammenfassung}

$\nabla$

Die inguinofemorale Lymphonodektomie stellt nach aktuellen Leitlinien das Standardverfahren beim Vulvakarzinom dar. Aufgrund erhöhter Raten an Wundheilungsstörungen, Lymphozelen und Lymphödemen könnten alternative Behandlungsmethoden insbesondere für nodalnegative Patientinnen zu einer Senkung der krankheitsassoziierten Morbidität und zu einer Steigerung der Lebensqualität führen. Die Sentinellymphonodektomie stellt beim unifokalen Mammakarzinom (klinisch unauffällige Axilla) den Goldstandard dar, und Studien zum Einsatz beim Vulvakarzinom weisen vielversprechende Ergebnisse auf. Bisher wurde in lediglich einer einarmigen, nicht randomisierten Studie die Wertigkeit dieser Methode überprüft. In einer Umfrage unter 41 deutschsprachigen Kliniken wurde 2010 die Verbreitung der Sentinellymphknotentechnik im Vergleich zur inguinofemoralen Lymphonodektomie erfasst. Die Kliniken wurden nach Größe und nach Anzahl der Vulvakarzinom-Patientinnen unterteilt. Erfasst wurde, welche Art der Lymphonodektomie nach welchen Entscheidungskriterien angewandt wird. Abschließend wurde die Bereitschaft zur Teilnahme an einer klinisch-prospektiven Studie zur Evaluation der Sentinellymphonodektomie beim Vulvakarzinom ermittelt. Die Mehrheit der Befragten (73\%) hatte Erfahrung mit dieser Technik beim Vulvakarzinom. In $27 \%$ der Kliniken wurde die inguinofemorale, in $10 \%$ die Sentinellymphonodektomie und in $63 \%$ wurden beide Methoden angewandt. Eine Komplettierung der Sentinellymphknotentechnik wurde in $24 \%$ der Kliniken grundsätzlich durchgeführt. Bei der Sentinellymphonodektomie gaben $20 \%$ der Befragten an, gemäß Kriterien zu verfahren, die in den Konsensusempfehlungen empfohlen wurden. Die Mehrheit der befragten Kliniken würde an einer randomisierten klinisch-prospektiven Studie zur Evaluation der 
sentinel lymph node biopsy alone in accordance with the criteria of the consensus recommendations. The majority of the investigated institutions were willing to participate in a randomised prospective clinical study to evaluate the effectiveness of sentinel lymph node sampling in patients with vulvar cancer.
Wertigkeit der Sentinellymphonodektomie beim Vulvakarzinom teilnehmen.

\section{Introduction}

\section{$\nabla$}

In Germany, approximately 1600 women develop vulvar cancer every year, and around 620 women die of it. The incidence of vulvar cancer is approx. $2.5 / 100000$ and the mortality is $1.3 / 100000$ (RKI, 2006), although recent calculations by the Association of Population-based Cancer Registries in Germany indicate that the number of new cases every year in Germany may range between 3400 and 4000 . The most common entity is squamous cell carcinoma (80-90\%) [1]. The data from the Cancer Registries shows enormous differences between federal states in Germany with regard to age-specific incidence of vulvar cancer, which ranges from 2.1 to 8.1 (http://www.krebsregister-sh.de/datenbank/ Vulva2011.pdf). The incidence of higher-grade HPV-associated vulvar intraepithelial neoplasias (VIN 3) is increasing, particularly among younger women [2-4]. One of the most significant prognostic factors for vulvar cancer is the presence or absence of lymph node metastasis. Depending on tumour size and infiltration depth, the standard surgical therapy for vulvar cancer consists of radical local tumour excision or complete/partial vulvectomy with unilateral or bilateral inguino-femoral lymphadenectomy. Excision of the inguinal lymph nodes does not merely remove potential lymph node metastasis, it also facilitates the correct staging for subsequent therapies and provides important information for disease prognosis. The argument for aggressive surgery in vulvar cancer is the high risk of death from missed inguinal involvement with subsequent regional or systemic metastasis. The argument against radical surgery is that approx. $70 \%$ of patients treated by complete removal of the inguinal lymph nodes had no metastasis [5-8]. Moreover, the radical surgical approach has a high morbidity: two thirds of patients subsequently have problems with wound healing, or go on to develop infections, lymphoceles or lymphoedema of the legs after removal of the inguinal lymph nodes [8-11,21,22].

Use of the sentinel lymph node technique could potentially be a less radical alternative in patients with vulvar cancer.

Forty-one hospitals treating differing numbers of patients for vulvar cancer were investigated. The survey aimed to evaluate the use of the sentinel lymph node technique to treat patients with vulvar cancer in Germany and compare the use of this technique with complete inguino-femoral lymphadenectomy. The survey investigated the extent to which hospitals complied with consensus recommendations and the willingness of hospitals to participate in a prospective clinical multicentre study to evaluate the oncological effectiveness of the sentinel lymph node technique in patients with vulvar cancer under real conditions.

\section{Methods \\ $\nabla$}

In a survey of hospitals performed by the Study Group for Gynaecological Oncology (AGO) in 2010, 41 hospitals in Germany answered questions on their use of the sentinel lymph node technique compared with complete inguino-femoral lymphadenectomy in patients with invasive vulvar cancer. The hospitals were divided into 4 categories: university hospitals, hospitals offering maximum care, tertiary care facilities and general hospitals. The hospitals were also differentiated into 4 groups according to the numbers of patients with vulvar cancer operated on annually: $>10$ patients/year, 7-10 patients/year, 4-6 patients/year and <3 patients/year. The gynaecological surgeons were asked about their experience with the sentinel lymph node technique for the treatment of breast cancer, endometrial cancer, cervical and vulvar cancer and about the surgical procedures used for lymph node dissection in patients with invasive vulvar neoplasias (inguino-femoral lymphadenectomy alone, full removal of lymph nodes with extirpation of the sentinel lymph nodes, or the sentinel lymph node technique alone, where indicated). If sentinel lymph node dissection alone was done, the preoperative criteria used in the respective hospital were investigated together with the incidence of inguinal lymphadenectomies performed to complete the procedure. Hospitals were also asked whether they were prepared to participate in a prospective clinical multicentre study to evaluate the oncological effectiveness of the sentinel lymph node technique in patients with vulvar cancer. The results of the survey were analysed using descriptive statistics.

\section{Results}

$\nabla$

Of the 41 German hospitals which participated in the survey, $44 \%$ $(n=18)$ were university hospitals, $19 \%(n=8)$ were hospitals offering maximum care, $22 \%(n=9)$ were tertiary care facilities, and $15 \%(n=6)$ were general hospitals. As regards the number of patients with invasive vulvar cancer treated, $54 \%(n=22)$ of the hospitals treated $>10$ patients/year, $22 \%(n=9)$ of hospitals treated between 7 and 10 patients/year, 19\% $(n=8)$ treated $6-4$ cases/year and $5 \%(n=2)$ of hospitals treated $<4$ patients/year ( Fig. 1). Almost all of the hospitals had some experience of the

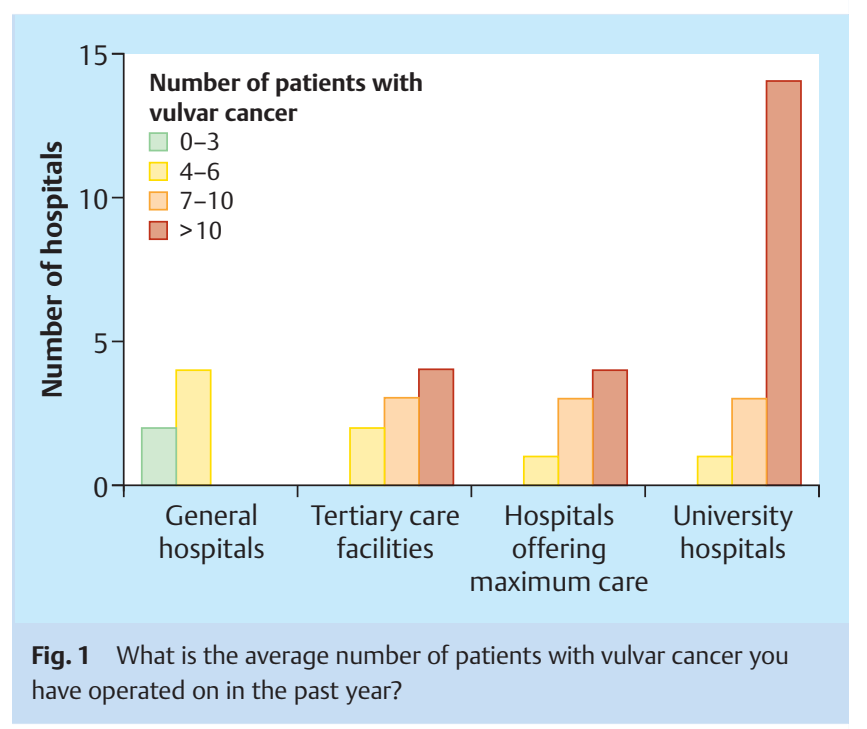




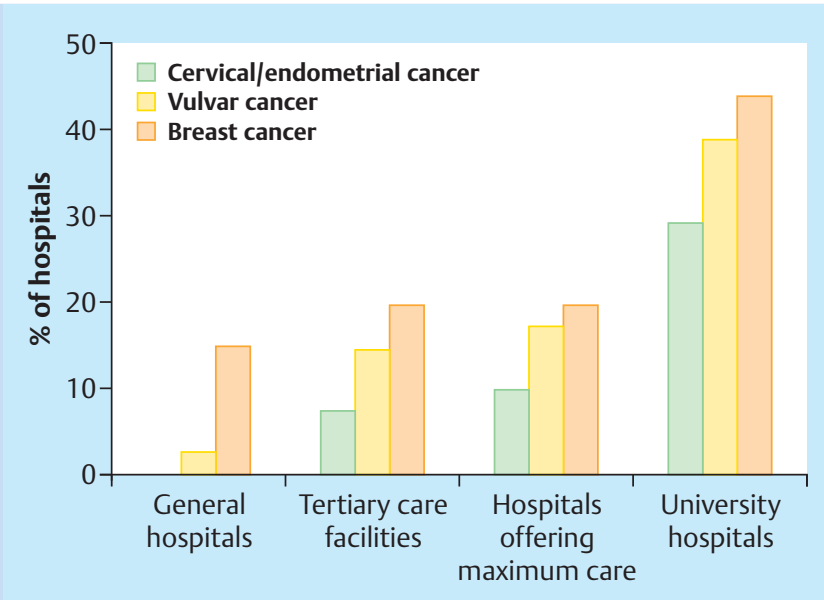

Fig. 2 How experienced are you in sentinel lymph node dissection?

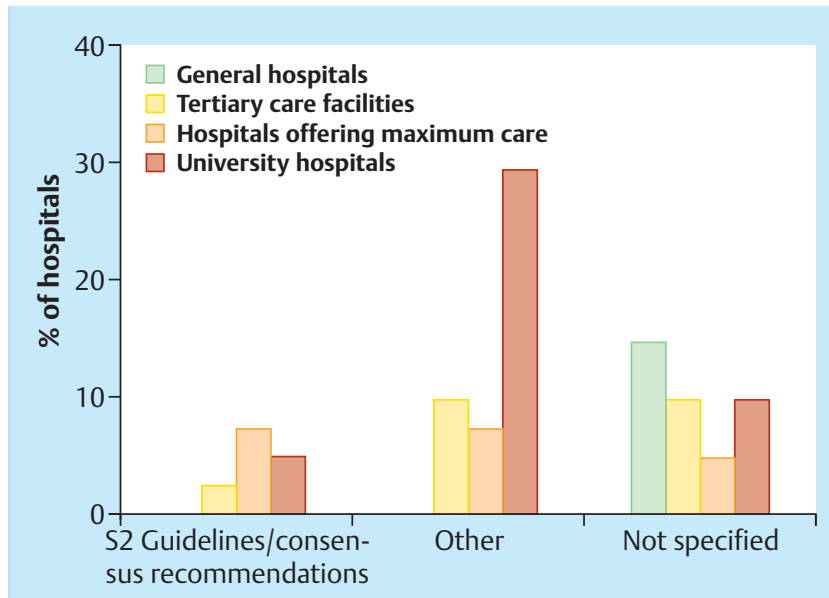

Fig. 3 What is your technique for lymphadenectomy in patients with vulvar cancer?

nuclide labelling and intraoperative detection were reported to have a high sensitivity, a high negative predictive value and a low false-negative rate of less than $3 \%$ [13].

127 patients who underwent supplementary lymphadenectomy were included in the German multicentre sentinel lymph node study of the AGO Vulva. The sensitivity was $92.3 \%$ and the falsenegative rate was $7.7 \%$ [14]. The results of the prospective observational GROINSS-V1 study for the period 2000 to 2006 were published in 2008. A total of 457 patients from 15 large gynaecological-oncological centres were included in this study. However, follow-up was short, with 276 patients followed up for 35 months and a total of 202 patients followed up for at least 24 months. The rate of inguino-femoral local recurrence was $2.9 \%$ and the median interval to recurrence was 12 months. However, the detection of metastasis in the sentinel lymph node was only possible using pathologic ultrastaging, (i.e. serial processing and immunohistochemical staining for cytokeratin [ $\bullet$ Figs. 5 and 6]), otherwise metastasis would have been missed in $42 \%$ of cases. Six of the 8 patients with inguino-femoral recurrence died. Two of them had multifocal recurrence, two patients had micrometastasis of the sentinel lymph node not found at primary diagnosis,

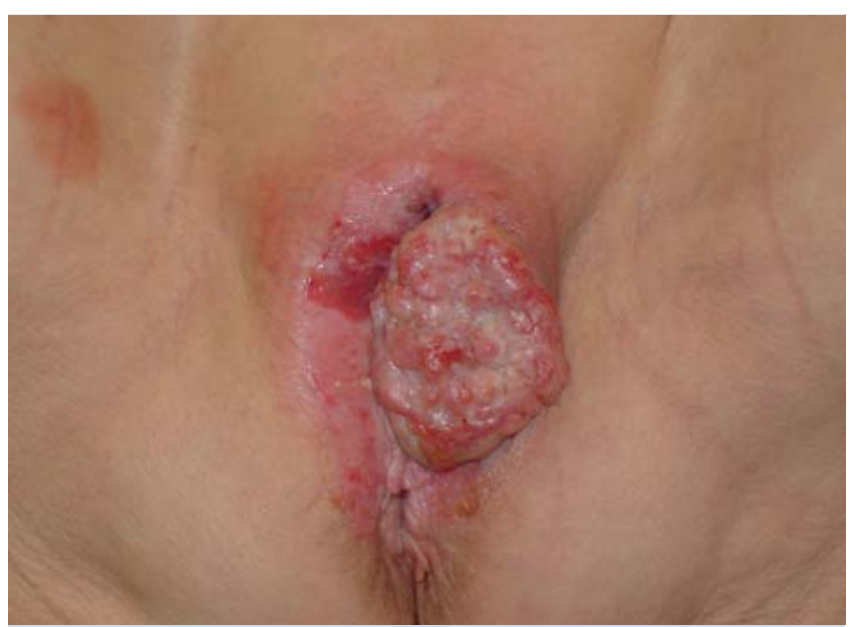

Fig. 4 Vulvar cancer extending from the left labium majus. 


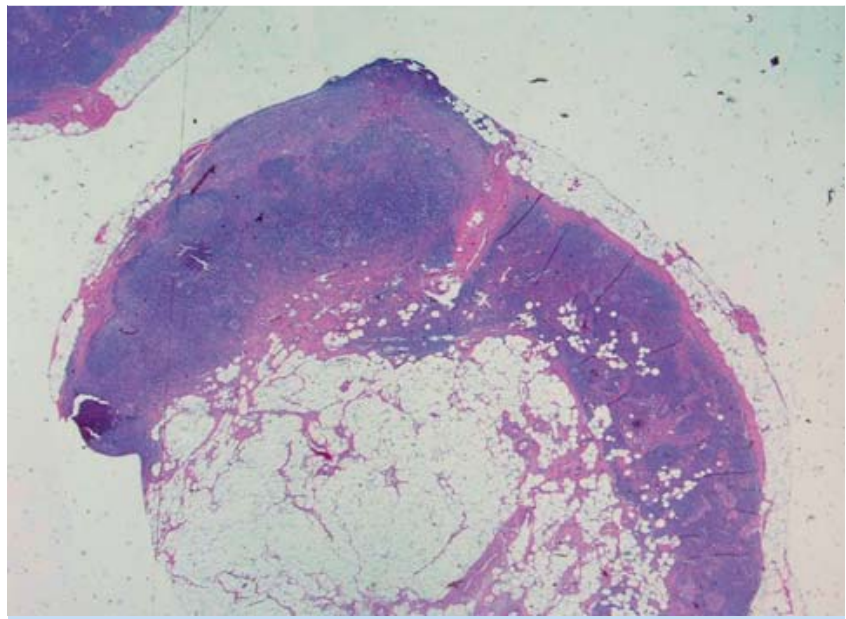

Fig. 5 Conventional H\&E staining shows no indication of sentinel lymph node metastasis.

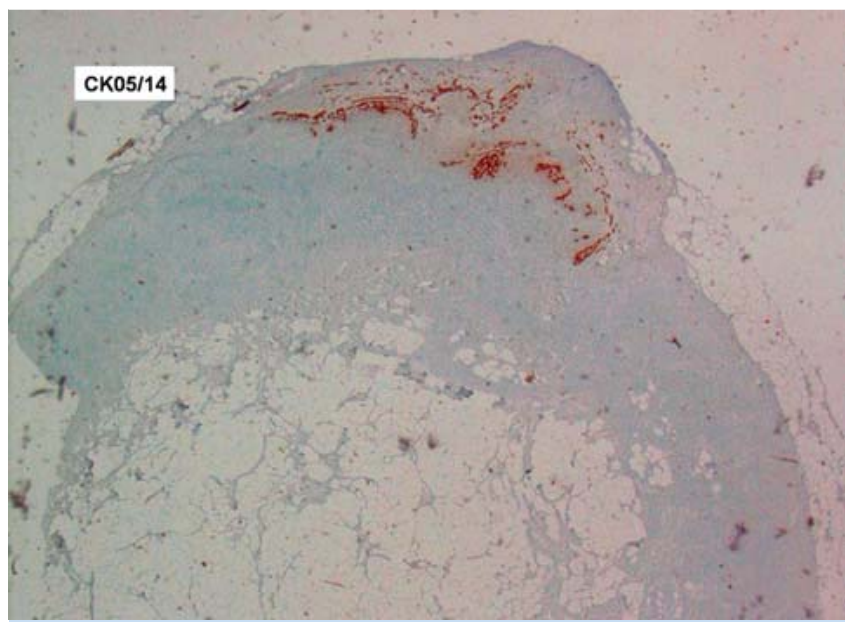

Fig. 6 Ultrastaging of the same sentinel lymph node: serial processing and immunohistochemistry (cytokeratin CK 05/14) shows metastatic involvement. and in 2 only one sentinel lymph node was dissected instead of the two detected at preoperative lymph scintigraphy. Thus, inguino-femoral recurrence was associated with a fatal outcome in most patients with vulvar cancer even after secondary surgery or radiotherapy. Surprisingly, the EORTC observational study did not find a strong difference in quality of life between patients treated with sentinel lymph node dissection and patients treated by complete lymphadenectomy $[12,15]$.

The GROINSS-V2 study was initiated in January 2006, based on results of the GROINSS-V1 study which had demonstrated the importance of adjuvant therapy in patients with positive sentinel lymph node involvement. One of the conclusions of the GROINSS-V1 study was that additional therapy was indicated if metastasis of any size was detected during sentinel lymphadenectomy. Although elective radiotherapy is already being used successfully in the therapy of squamous cell carcinoma of other origin, the data on the safety of this method for the treatment of patients with primary vulvar cancer and sentinel lymph node metastasis is controversial. In a case-control study by Manavi et al., 65 patients with $\mathrm{T} 1$ vulvar cancer and clinically unsuspicious inguino-femoral lymph nodes underwent inguino-femoral radiotherapy. The local rate of recurrence was 4.6\% [16]. The study by Perez et al. [17] reported a recurrence rate of $10.5 \%$, but tumour sizes in their study were larger (T1/T2) than in the study by Manavi et al. In a randomised control study, Stehmann et al. compared the outcomes after primary surgery for T1, T2 and T3 vulvar tumours with those after inguino-femoral radiotherapy of clinically unsuspicious lymph nodes. There was no recurrence after surgery ( $0 / 25)$, while $5 / 27$ patients had recurrence after primary radiotherapy (rate of recurrence: 18.5\%) [18]. The criticism that could be levelled at all of these studies is that deep lymph nodes were probably not adequately irradiated. In a retrospective analysis of 227 patients with vulvar cancer, the rates of local recurrence were similar for patients treated with inguino-femoral lymphadenectomy alone, with radiotherapy alone and with a combination of both methods. The authors' conclusion was that elective inguino-femoral radiotherapy in patients with vulvar cancer and minimal or microscopic tumours could help prevent most cases of local recurrence [19]. Based on the results of all studies to date, irradiation therapy could be used to prevent local recurrence in patients with vulvar cancer and minimal/microscopic inguino-femoral tumours, provided the dosage is adequate, the target volume is correct and the penetration depth is sufficient.

The rationale behind the GROINSS-V2 follow-up study on sentinel lymph node metastasis was to evaluate the safety of combined sentinel lymph node dissection and radiation compared with the standard procedure of additional inguino-femoral lymphadenectomy. According to the study protocol of the GROINSS-V2 study, adjuvant radiotherapy with 50 Gy was indicated in cases with sentinel lymph node involvement. Inclusion criteria for the study were squamous tumours with diameters of $<4 \mathrm{~cm}$, an infiltration depth $>1 \mathrm{~mm}$ and no clinical indications of tumours in the inguino-femoral region. Criteria for terminating the study were defined prior to the start of the study; the criterion was a rate of recurrence of between 4 and a maximum of $6 \%$ for a collective of 135 recruited patients with vulvar cancer. In June 2010, no further patients were enrolled in the study as the upper limit for the rate of recurrence of $6 \%$ had been exceeded. At that point a total of 82 patients had been enrolled in the study, and 10 of these had recurrence in the inguinal region. An analysis of the cases in accordance with the study protocol showed that the number of inguinal recurrences was significantly higher in patients with sentinel lymph node metastases $>2 \mathrm{~mm}$ (9/45 vs. $1 / 46, \mathrm{p}=0.008$ ). In addition, extracapsular extension of a lymph node metastasis was also associated with a higher risk of inguinal recurrence $(4 / 15$ vs. 5/74, $\mathrm{p}=0.04)$.

The current S2 guidelines specifically emphasise the importance of careful examination and dissection prior to and during sentinel lymph nodectomy in patients with vulvar cancer. Prior to surgery the patient must be fully informed about the potentially higher rate of recurrence and the associated poorer prognosis. Patients must be followed up closely after surgery. According to the S2 guidelines, this method should only be used in patients with a tumour size $\leq 4 \mathrm{~cm}$ (FIGO I) and no clinical or sonographic evidence of lymph node metastasis. Surgeons must be experienced in the use of technique, with at least 10 previous sentinel lymph node dissections performed in patients with vulvar cancer. Biopsied tissue should be fully embedded and serial sections cut at intervals of $200 \mu \mathrm{m}$ for immunohistochemical ultrastaging 
(anti-cytokeratin pan antibodies) to detect micrometastasis. If histology is negative for metastasis, immunohistochemistry can be used for the detection of epithelial markers [20]. The patient should additionally be informed about the necessity for secondary inguino-femoral lymphadenectomy in the event of micrometastasis. A review of all currently available study results shows that the use of sentinel lymph node dissection alone is acceptable provided that all of the above criteria as described in the S2 guidelines are met.

The 6th Biennial International Sentinel Node Society Meeting 2008 held in Sydney, Australia formulated similar consensus recommendations on the use of sentinel lymph node dissection to treat patients with unifocal vulvar cancer. They found that the experience of the surgical team played an important role, with better results reported for surgeons who operated greater numbers of patients per year, generally more than 5-10 cases annually. The criteria for performing the procedure in patients with unifocal squamous cell carcinoma of the vulva were a maximum tumour diameter of $\leq 4 \mathrm{~cm}$, preoperative lymph scintigraphy with identification and extirpation of all sentinel lymph nodes and the identification of the sentinel lymph nodes on both sides in cases with midline tumours. However, they recommended performing complete lymphadenectomy when inconsistencies or suspicious lymph nodes were present. The recommended postoperative follow-up of patients was at 3-month intervals.

In our survey of the criteria for sentinel lymph node dissection in patients with vulvar cancer, only $20 \%$ of the surveyed institutions stated that they carried out sentinel lymph node extirpation in accordance with the above-listed criteria ( $\mathbf{O}$ Fig. $\mathbf{3}$ ). This could indicate these recommendations have not been sufficiently disseminated and therefore that the preconditions for performing sentinel lymphadenectomy alone in patients with vulvar cancer are insufficiently known. However, our survey found that experience of the sentinel lymph node technique was increasing, although experience largely depended on hospital size ( 0 Fig. 2). $73 \%$ of surveyed hospitals were prepared to participate in further evaluations of this technique offering the possibility of further prospective clinical multicentre studies. Finally, it is important to qualify the results of our study by noting that only a limited number of the questionnaires distributed using the email list of the AGO were returned, and that this evaluation therefore does not reflect the real situation in German hospitals.

The modified GROINSS-V2 study could provide new information. It aims to evaluate the efficacy of adjuvant radiotherapy compared to supplementary inguino-femoral lymph node dissection in patients with unifocal vulvar cancer and sentinel lymph node metastasis of $<2 \mathrm{~mm}$. AGO Vulva has planned a clinical observational study with strict inclusion criteria to evaluate the oncological safety of sentinel lymph node dissection alone in patients with vulvar cancer. In view of the rarity of this tumour entity, it is almost impossible to carry out a prospective randomised study, which would otherwise be preferable.

\section{Conclusion}

$\nabla$

The sentinel lymph node technique is increasingly being used in Germany to treat patients with invasive vulvar cancer. The current criteria for the comprehensive implementation of the sentinel lymph node technique to treat patients with vulvar cancer are based on the study of van der Zee et al. [12,15]. Using the limited data available, our 2010 study showed that only a few hospitals used the sentinel lymph node technique in accordance with the guidelines on vulvar cancer or the strict conditions prescribed by international consensus recommendations. The majority of patients who had sentinel lymph node extirpation additionally underwent radical resection of the inguino-femoral lymph nodes, a procedure which is associated with increased morbidity. Only a few of the surveyed hospitals stated that they complied strictly with the criteria of the S2 guidelines published in 2008 and with the international consensus recommendations published in 2009. More information and a better dissemination of information are necessary. AGO Vulva has planned a clinical observational study to evaluate the oncological safety of the sentinel lymph node technique in patients with vulvar cancer. More than $73 \%$ of hospitals that took part in our survey were prepared to participate in a prospective clinical observational study. However, given that the incidence of invasive vulvar cancer is $2.5 /$ 100000 per year, it will be difficult to recruit sufficient numbers of patients to obtain statistically valid data.

\section{Conflict of Interest}

$\nabla$

The authors declare that they have no financial ties to any company mentioned in this article.

\section{References}

1 Hording U, Junge J, Daugaard S et al. Vulvar squamous cell carcinoma and papillomaviruses: indications for two different etiologies. Gynecol Oncol 1994; 52: 241

2 Jones RW, Rowan DM. Vulvar intraepithelial neoplasia III: a clinical study of the outcome in 113 cases with relation to the later development of invasive vulvar carcinoma. Obstet Gynecol 1994; 84: 741

3 Sturgeon SR, Brinton LA, Devesa SS et al. In situ and invasive vulvar cancer incidence trends (1973 to 1987). Am J Obstet Gynecol 1992; 166 : 1482

4 Iversen T, Tretli S. Intraepithelial and invasive squamous cell neoplasia of the vulva: trends in incidence, recurrence, and survival rate in Norway. Obstet Gynecol 1998; 91: 969

5 Hacker NF, Leuchter RS, Berek JS et al. Radical vulvectomy and bilateral inguinal lymphadenectomy through separate groin incisions. Obstet Gynecol 1981; 58: 574

6 Burger MP, Hollema H, Emanuels AG et al. The importance of the groin node status for the survival of $\mathrm{T} 1$ and $\mathrm{T} 2$ vulval carcinoma patients. Gynecol Oncol 1995; 57: 327

7 Bell JG, Lea JS, Reid GC. Complete groin lymphadenectomy with preservation of the fascia lata in the treatment of vulvar carcinoma. Gynecol Oncol 2000; 77: 314

8 Knopp S, Nesland JM, Trope C. SLNB and the importance of micrometastases in vulvar squamous cell carcinoma. Surg Oncol 2008; 17: 219

9 Robison K, Steinhoff MM, Granai CO et al. Inguinal sentinel node dissection versus standard inguinal node dissection in patients with vulvar cancer: A comparison of the size of metastasis detected in inguinal lymph nodes. Gynecol Oncol 2006; 101: 24

10 Rouzier $R$, Haddad B, Dubernard $G$ et al. Inguinofemoral dissection for carcinoma of the vulva: effect of modifications of extent and technique on morbidity and survival. J Am Coll Surg 2003; 196: 442

11 Gaarenstroom KN, Kenter GG, Trimbos JB et al. Postoperative complications after vulvectomy and inguinofemoral lymphadenectomy using separate groin incisions. Int J Gynecol Cancer 2003; 13: 522

12 van der Zee AG, Oonk MH, de Hulla JA et al. Sentinel node dissection is safe in the treatment of early-stage vulvar cancer. J Clin Oncol 2008; 26: 884-889

13 Malur S, Altgassen C, Ackermann S et al. Wertigkeit des Sentinellymphknotens in der gynäkologischen Onkologie. Geburtsh Frauenheilk 2003; 63: R185-R204

14 Hampl M, Hantschmann P, Michels Wet al. Validation of the accuracy of the sentinel lymph node procedure in patients with vulvar cancer: results of a multicenter study in Germany. Gynecol Oncol 2008; 111: 282 
15 Oonk MH, van Hemel BM, Hollema H et al. Size of sentinel-node metastasis and chances of non-sentinel-node involvement and survival in early stage vulvar cancer: results from GROINSS-V, a multicentre observational study. Lancet Oncol 2010; 11: 646

16 Manavi M, Berger A, Kucera E et al. Does T1, N0-1 vulvar cancer treated by vulvectomy but not lymphadenectomy need inguinofemoral radiation? Int J Radiat Oncol Biol Phys 1997; 38: 749-753

17 Perez CA, Grigsby PW, Chao C et al. Irradiation in carcinoma of the vulva: factors affecting outcome. Int J Radiat Oncol Biol Phys 1998; 42: 335-344

18 Stehman FB, Bundy BN, Thomas G et al. Groin dissection versus groin radiation in carcinoma of the vulva: a Gynecologic Oncology Group study. Int J Radiat Oncol Biol Phys 1992; 24: 389-396
$19 \mathrm{Katz}$ A, Eifel PJ, Jhingran A et al. The role of radiation therapy in preventing regional recurrences of invasive squamous cell carcinoma of the vulva. Int J Radiat Oncol Biol Phys 2003; 57: 409-418

20 Regauer S. Histopathological work-up and interpretation of sentinel lymph nodes removed for vulvar squamous cell carcinoma. Histopathology 2009; 55: 174

21 Rahhal-Schupp J, Grimm C, Aust S et al. Prognostische Bedeutung des Serummarkers Gamma-Glutamyltransferase bei Patientinnen mit Vulvakarzinom. Geburtsh Frauenheilk 2012; 72 - A9

22 Natter C, Rahhal J, Polterauer S et al. Einfluss der Lymphknotendichte auf das Gesamtüberleben bei Patientinnen mit Vulvakarzinom. Geburtsh Frauenheilk 2011; 71 - A12

Deutschsprachige Zusatzinformationen online abrufbar unter: www.thieme-connect.de/ejournals/toc/gebfra. 